\title{
Impacts of Climate Change on the Hydro- Climatology and Performances of Bin El Ouidane Reservoir: Morocco, Africa
}

\author{
Abdellatif Ahbari, Laila Stour, and Ali Agoumi
}

\section{Contents}

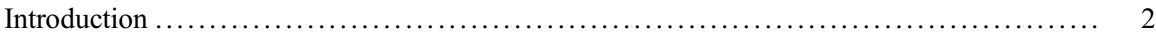

Overview of the Adopted Framework of Analysis ................................ 3

Presentation of the Dam of Bin El Ouidane and the Impacts Assessment Framework .... . 3

Performance Criteria Used to Assess the Performances of the Reservoir .............. 5

Description of the Climate Models and Scenarios ............................... 6

Description of the Models Embedded in the Framework ......................... 7

Evaluation of the Water Demand and the Impact Assessment Criteria ................. 7

The Observed Impacts on Hydro-Climatology and Reservoir's Performances .............. 8

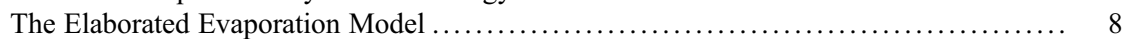

CC Impacts on HC and Management Variables ................................ 10

CC Impacts on the Performances of BEO-AEO Reservoir ........................ 17

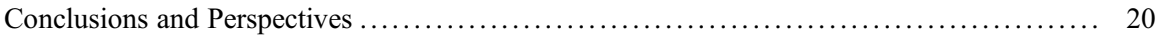

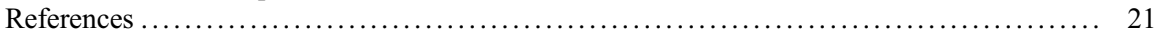

\section{Abstract}

In arid and humid contexts, dams' reservoirs play a crucial role in water regulation and flood control. Under the projected climate change (CC) effects, even a preoptimized management approach (MA) of a reservoir needs to be assessed in this projected climate. This chapter aims to assess the impacts of $\mathrm{CC}$ on

This chapter was previously published non-open access with exclusive rights reserved by the Publisher. It has been changed retrospectively to open access under a CC BY 4.0 license and the copyright holder is "The Author(s)". For further details, please see the license information at the end of the chapter.

A. Ahbari $(\bowtie) \cdot$ L. Stour

Laboratory of Process Engineering and Environment, Faculty of Sciences and Techniques, Hassan II University of Casablanca, Mohammedia, Morocco
A. Agoumi
Laboratory of Civil Engineering, Hydraulic, Environment and Climate Change, Hassania School of Public Works, Casablanca, Morocco 
the Hydroclimatic $(\mathrm{HC})$ variables of the basin upstream the reservoir of Bin El Ouidane (Morocco), and the effects on the performances of its preoptimized MA. The applied Top-Down assessment procedure included CORDEX climate projections, hydrological, siltation, evaporation, and management models. Concerning the $\mathrm{HC}$ variables, the results obtained concord with those reported in the literature in terms of trend, but not always in terms of intensity of change. On the other hand, the projections expected a decrease in the performances of the reservoir, except for criterion allocations' standard deviation, calibrated during the optimization. Also, interesting conclusions have been found like: the change in precipitation dominant form, the accentuation of the pluvial hydrological regime, the advanced snow melting due to the temperature increase. This chapter presents a typical case study on how to use climate projections for reservoir MA adaptation, without being highly and negatively influenced by the climate model uncertainties.

\section{Keywords}

Reservoir · Impact · CORDEX · Management $\cdot$ Performance criteria $\cdot$ Bin El Ouidane

\section{Introduction}

Dams' reservoirs play a crucial role in the attenuation of the intra and interannual water resources heterogeneity. In fact, either in arid or humid context, these hydraulic infrastructures permit the flood control and assure the satisfaction of different water demand. In Morocco, the dam construction policy had helped in mitigating the impacts of intra-annual precipitations variability, drought periods, and massive flood events. Nonetheless, according to global and national climate projections reports (IPCC 2014; MEMEE 2016), the potential impacts of climate change (CC) can alter partially or totally this role of water regulation. Moreover, the adaptation to future CC effects should be considered in both design and exploitation phases of dams' reservoirs. On one hand, the adaptation in the design phase should focus on the change of the available water supply (Nassopoulos et al. 2012), the frequency and intensity of floods (Tofiq and Guven 2014), and the sediment yield volumes (Bussi et al. 2014). On the other hand, the adaptation during the exploitation phase is more oriented toward the regular update of the MA, and of its parameters (Zhang et al. 2017). Nonetheless, the update of MAs should not be limited to historical data, but the use of future climate projections resulting from global and regional climate models (RCM) is a path that requires further investigation (Brown et al. 2012). Several methodologies were attempted to adapt water planning to CC (Borison and Hamm 2008; Morgan et al. 2009). Nevertheless, managers still have a suspicious attitude toward climate projections (Means et al. 2010). Nowadays, it is clear that with all the problems related to observational data quality and accessibility, some models' aspects inefficiencies, uncertainties, diversified range of projected impacts, greenhouse emissions scenarios diversity, and the deduction of conclusions from the usage of climate projections is risked and limited (Brient 2020; Sellami et al. 2016). 
Other than the use of climate projections to assess a preupdated MA, they can also be beneficial to highlight some negative aspects of the management to correct, or other positive points to enhance.

This chapter presents an assessment of the potential impacts of future CC projections on the Hydroclimatic $(\mathrm{HC})$ variables on the basin upstream the dam reservoir of Bin El Ouidane, and the impacts on the future performances of the preoptimized Management Approach (MA) of this reservoir. In addition, the chapter aims to converge to conclusions that can be useful in the enhancement of the preoptimized approach. Furthermore, a comprehensive procedure that can be generalized to adapt reservoir MAs of other reservoirs worldwide is proposed.

\section{Overview of the Adopted Framework of Analysis}

\section{Presentation of the Dam of Bin El Ouidane and the Impacts Assessment Framework}

The hydraulic complex of Bin El Ouidane-Ait El Ouarda (named hereafter "BEOAEO") is located in the high Atlas of Morocco, and composed of the major $1500 \mathrm{Mm}^{3}$ reservoir of Bin El Ouidane (BEO), and its $4 \mathrm{Mm}^{3}$ compensatory reservoir Ait El Ouarda (AEO). BEO-AEO was constructed in 1953 to satisfy the water demand of: (1) irrigation perimeters of Beni-Moussa and Tassaout-Aval; (2) drinking water of Afourer, Beni-Mellal, and neighboring villages; (3) production of hydroelectricity; and (4) flood control (Fig. 1).

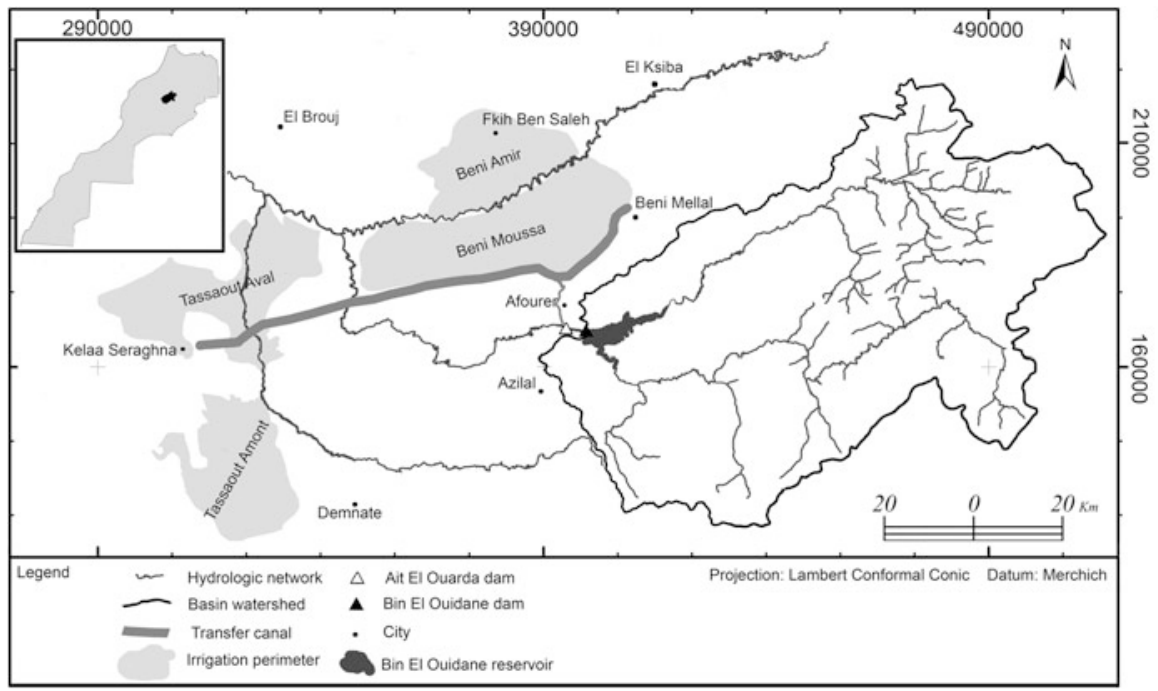

Fig. 1 Geographical map locating the basin of BEO, the dams, and the irrigated perimeters 


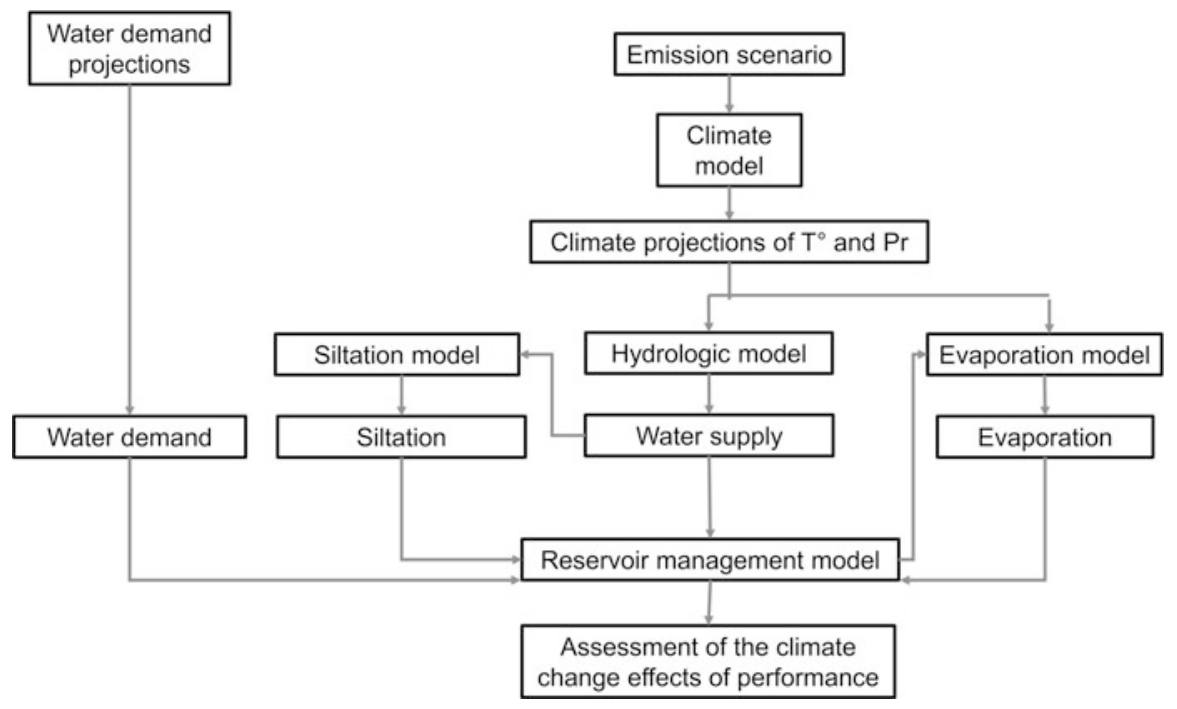

Fig. 2 Typical top-down procedure to assess the $\mathrm{CC}$ effects on reservoir performances

The BEO-AEO reservoir complex is located at the outlet of an upstream basin of $6500 \mathrm{~km}^{2}$. The analysis of the past hydro-climatologic variables evolution within the basin of BEO (Ahbari et al. 2017) shows an augmentation trend of the annual temperature $\left(+0,4{ }^{\circ} \mathrm{C}\right.$ in $1989-2013$ and of evaporation from the reservoir (+470 mm in 1976-2006), as stagnation of annual rainfall (around $400 \mathrm{~mm}$ during 1976-2014) and a substantial drop of the annual water supply to the reservoir by almost 50\% after 1976 (from $1350 \mathrm{Mm}^{3}$ during $1939-1976$ to $750 \mathrm{Mm}^{3}$ during 1976-2014).

In order to assess the impacts of future $\mathrm{CC}$ effects on the $\mathrm{HC}$ variables inside the basin located upstream the complex, the management variables of BEO-AEO and the performances of BEO-AEO, the typical Top-Down procedure described in Fig. 2 is used.

As shown in Fig. 2, the starting point is to choose a climate scenario. The appropriate way to proceed is by testing at least two opposite scenarios: one optimistic and another pessimistic. This will permit to have an idea about the variation interval of the eventual impacts. Then, the selected climate scenario will drive a climate model in order to output the future projections of temperature and precipitations for a given area. In general, the regional climate model is more suitable for the assessment of CC impacts assessment in basin-scale studies (Singh et al. 2019). After that, the resulting climate projections series will be used as direct entries for a prevalidated hydrologic and evaporation models. Once the projected water supply series are calculated, they will be inputted to a prevalidated siltation model to estimate the projected annual siltation volumes. The next step is to run the reservoir management model using the projected series from the hydrologic, siltation, and evaporation models, in association with the projected water demand. Finally, by using representative performance criteria, the results of the projected reservoir 
behavior are analyzed and compared to the performances outputted by the preoptimized MA described in detail in Ahbari et al. (2019).

Since this chapter is more concerned about the daily management behavior, a daily time step is adopted. The reference period is between 1 March 1986 and 31 August 2015 (similar to the IPCC reference period for its AR5 report), and the projection period occupies the period between 1 March 2020 and 31 August 2049. The following subsections introduce the different components and models used in order to apply top-down assessment procedures to BEO-AEO.

\section{Performance Criteria Used to Assess the Performances of the Reservoir}

\section{The Reliability}

This criterion is calculated in relation to the duration of the demand satisfaction, as proposed by McMahon et al. (2006) in Eq. 1:

$$
R l=\frac{N b \_ \text {of_times } \_D_{t}=0}{n}
$$

where $D_{t}$ is the deficit at time step $t ; n$ is the number of time steps.

\section{The Resilience}

It is the probability that a state of demand's satisfaction follows a state of demand's dissatisfaction (Sandoval-Solis et al. 2011). The formula used is described in Eq. 2:

$$
R s=\frac{N b \_ \text {of_times_ } D_{t+1}=0 \_ \text {follows } \_D_{t}>0}{N b \_ \text {of_times_ } D_{t}>0}
$$

\section{The Vulnerability}

It is the likely deficit value of the system if a state of demand's dissatisfaction occurred (Hashimoto et al. 1982). In this chapter, the formula that estimates an average value of the likely deficit is adopted as shown in Eq. 3 (Sandoval-Solis et al. 2011):

$$
V u l=\frac{\sum_{t=1}^{n} D_{t} / N b \_ \text {of_times__ } D_{t}>0}{\text { water_demand }}
$$

\section{The Sustainability}

It is a criterion that attempts to unify in a unique value the information driven by more than one performance criterion. The reformulated Looks (1997) sustainability formula suggested by Sandoval-Solis et al. (2011) is the one used in the chapter (Eq. 4):

$$
S u s=\sqrt[3]{[R l \times R s \times(1-V u l)]}
$$




\section{The Allocations' SD}

This criterion permits to unveil to what extent a specific management approach has an unpredicted and unstable water allocations (Ahbari et al. 2019). Equation 5 details the calculation expression:

$$
S D=\frac{\sqrt{\sum^{t=1}\left(X_{t}-X_{m}\right)^{2} /(n-1)}}{\text { Water_demand }}
$$

where $X_{t}$ is the allocated volume at time step $t ; X_{m}$ is the average allocated volume; $n$ is the number of time steps.

\section{Description of the Climate Models and Scenarios}

As it was mentioned before, two representative concentration pathways (RCP) were used (Van Vuuren et al. 2011): the optimistic scenario "RCP 2.6" and the pessimistic scenario "RCP 8.5." The selection of the RCP 8.5 and 2.6 as assessment scenarios is driven by the fact that the objective of the chapter is to track the potential interval of plausible changes resulting from all levels of mitigation policies (no policy, weak, modest, below $2{ }^{\circ} \mathrm{C}$ policies). Therefore, the RCP 8.5 is chosen to represent the pessimistic trend, even though it is a highly unlikely case (Hausfather and Peters 2020), and the RCP 2.6 to simulate the optimistic tendency willing to keep the global warming below $2{ }^{\circ} \mathrm{C}$. Concerning the climate projections, the data from the COordinated Regional Climate Downscaling EXperiment (CORDEX; Giorgi et al. 2009) were employed. The data output used are the bias-corrected climate projections over the EUR-11 domain which contains our studied area. The bias-corrected CORDEX data are accessible via the link https://esgf-data.dkrz.de/search/cordex-dkrz/. By respecting the same specifications during the data filtration (same Regional Circulation Model (RCM) and driven Global Circulation Model (GCM)) for both RCP scenarios, only two RCM were available for use: RCA4 and REMO2009. These RCM are driven respectively in their boundaries conditions by the GCM: ICHECEC-EARTH and MPI-M-MPI-ESM-LR. The NetCDF files containing the biascorrected projections were downloaded for each variable-RCP-RCM triple, for the projection period 2020-2049. Since a global hydrologic model was used to simulate the streamflow in the basin, the calculation of the average projected series for the basin for each Variable-RCP-RCM triple was mandatory. So, the $6500 \mathrm{~km}^{2}$ basin upstream BEO-AEO is divided into a $11 \mathrm{~km}$ grid cells, and the projected series of each triple variable-RCP-RCM at the center of each cell are extracted. The transformation of the cell center coordinates from regular to rotated was done using the software AgriMetSoft (2017). Then, the average basin series for each triple are calculated by averaging the projected series for all cells. To get the projected series for each variable-RCP couple, an ensemble mean was calculated using the series of the two RCM, and then converted to IS units $\left({ }^{\circ} \mathrm{C}\right.$ and $\left.\mathrm{mm}\right)$. 


\section{Description of the Models Embedded in the Framework}

The hydrologic model used is the hydrologic modeling system (HMS) model, with a simple canopy and surface formalisms, the soil moisture accounting (SMA) as the loss method, the Clark Unit Hydrograph (Clark UH) as the transform method, and the exponential recession method to simulate the baseflow component. The model was calibrated and validated over the basin in previous works (Ahbari et al. 2018a, b). The HMS model of the basin was obtained after a training-validation and a detailed sensitivity analysis processes that permit to converge to the best HMS model in terms of efficiency. Nonetheless, it is necessary to highlight that this rainfallrunoff model exhibits some deficiency in the simulation of some flow peaks as described in Ahbari et al. (2018b). This deficiency was taken into consideration while interpreting and discussing the results of this chapter. About the siltation process in BEO reservoir, it is modeled using a preestablished model (Ahbari et al. 2018c) integrating sediment yield to the reservoir and the sediment consolidation phenomena. As described in detail in Ahbari et al. (2018c), the preestablished siltation model was able to simulate the observed time series of siltation in BEO using a genetic algorithm optimization process. For the evaporation from the reservoir water plane, it is estimated using a multiple linear regression model between the monthly evaporated volume as a dependent variable and the monthly average temperature, the monthly potential evapotranspiration (ETP) and the reservoir water level at the beginning of the month, as explanatory variables. The mentioned evaporation model was calibrated and validated for the purpose of this assessment study, and the results are shown in the results section.

Concerning the BEO-AEO management model, it is represented by an optimized version of the current MA practiced in BEO-AEO. The optimization of the current MA was done using the genetic algorithm, and its performances were evaluated in a two-step process: a training-validation and a sensitivity analysis processes. For brevity purposes, more details about the reservoir operations fulfilled by this model please refer to Ahbari et al. (2019).

\section{Evaluation of the Water Demand and the Impact Assessment Criteria}

Due to the lack of detailed data about the projection of the daily water demand for each user for the projected period of 2020-2049, the series of the projected daily water demand was constructed by extrapolating the current hypothetical water demand, using the available projected evolution ratio of the basin of Oum-ErRabia. In fact, the basin of BEO-AEO is part of the basin of Oum-Er-Rabia for which the projected evolution ratios in 2020, 2025, and 2030 are available. Beyond 2030, the same ratio as for 2030 is applied till the end of the projected period. The current hypothetical water demand refers to an annual water demand series represented by the year on which the releases from BEO-AEO are maximal. This hypothetical series should be the best to represent the current water demand series (which is inaccessible for the authors) since the daily deficits will be at their minimal values ever recorded. Nevertheless, it is important to notice that the constructed 
annual water demand at the 2030 horizon (constructed using the concept described above) is almost equal to the only information publically available about the annual water demand for BEO-AEO for the same horizon (annual water demand at the 2030 horizon).

To evaluate the impacts of $\mathrm{CC}$ on the $\mathrm{HC}$ variables inside the basin of BEO-AEO and on its management variables, two assessment criteria were used: the average values between the reference and the projected periods, and the intra-annual evolution of the $\mathrm{HC}$ variables. Additionally, the following criteria were used to assess the change in the performances of the BEO-AEO complex in satisfying the water demand: the deficit, the reliability, the resilience, the vulnerability, the sustainability, and the standard deviation of allocations.

\section{The Observed Impacts on Hydro-Climatology and Reservoir's Performances}

\section{The Elaborated Evaporation Model}

The calibration period starts from March 1986 to February 2002, and the validation begins in March 2002 and finishes in December 2008. Figure 3 shows the linear regressions during the calibration and the validation periods.

As seen in Fig. 3, the linear regression is clear, important $\left(\mathrm{R}^{2}=0.72\right.$ for calibration and 0.76 for validation), and statistically significant at $5 \%$ level (pvalue $<0.0001)$. The resulting multiple linear regression relates the monthly evaporated volume from the reservoir of BEO to three explanatory variables as described in Eq. 6:

$$
V_{E V P}=-46.03+0.06^{*} H_{W L}+0.26^{*} T+0.25^{*} E T P
$$

where $V_{E V P}$ is the monthly evaporated volume $\left(\mathrm{Mm}^{3}\right) ; H_{W L}$ is the water level in the reservoir of BEO at the beginning of the month $(\mathrm{m}) ; T$ is the average monthly temperature $\left({ }^{\circ} \mathrm{C}\right) ; E T P$ is the monthly potential evapotranspiration $(\mathrm{mm}) . H_{W L}$ and $T$ are both based on observed values of water level in the reservoir of BEO and the average temperature at the gauge of Tilouguite. The ETP was calculated based on the formulae (Eq. 7) dedicated for rainfall-runoff modeling purposes proposed by Oudin et al. (2005).

$$
\begin{aligned}
& E T P=\frac{R_{e}}{\lambda \cdot \rho} \frac{T_{a}+5}{100} \Rightarrow \text { if } T_{a}+5>0 \\
& E T P=0 \Rightarrow \text { otherwise }
\end{aligned}
$$

where ETP is the rate of potential evapotranspiration $\left(\mathrm{mm} \mathrm{day}^{-1}\right), R_{e}$ is extraterrestrial radiation which depends on latitude and Julian day $\left(\mathrm{MJ} \mathrm{m}^{-2} \mathrm{day}^{-1}\right), \lambda$ is the latent heat flux equals $2,45\left(\mathrm{MJ} \mathrm{kg}^{-1}\right), \rho$ is the density of water $\left(\mathrm{kg} \mathrm{m}^{-3}\right)$, and $T_{a}$ is mean daily air temperature $\left({ }^{\circ} \mathrm{C}\right)$. 
(a)

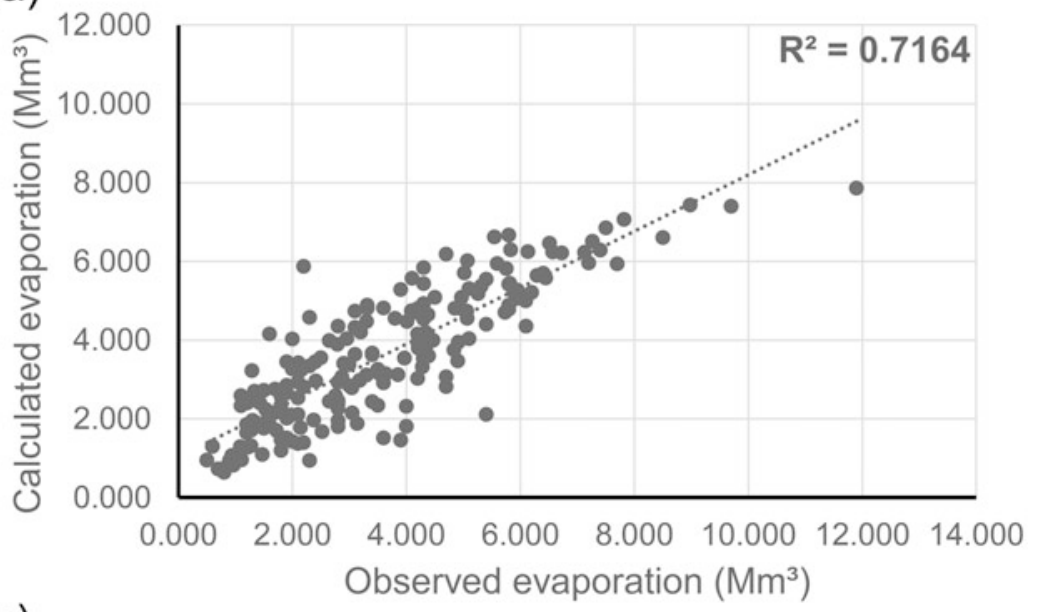

(b)

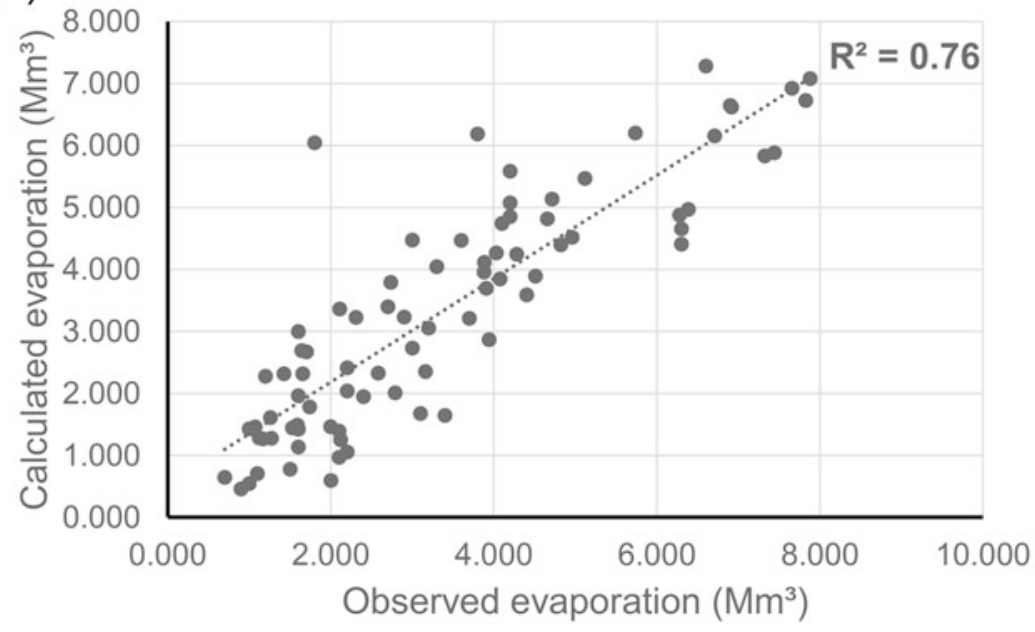

Fig. 3 Linear regression between observed and calculated evaporation during (a) calibration and (b) validation periods

By integrating the water level as an explanatory variable, the obtained equation implicitly integrates the most important parameter that controls the evaporation from the reservoir: the surface of the water plane. The regression would be more substantial if other variables data were available like humidity and wind speed (Condie and Webster 1997). 


\section{Impacts on HC and Management Variables}

\section{Change in Average Values}

Table 1 resumes the change in the average values of different $\mathrm{HC}$ and management variables between the reference and the projection periods.

The six key observations extracted from Table 1 are:

Firstly, negative impacts (qualified as negative because they alter directly or indirectly the performances of the reservoir) are suggested by both RCP for all variables, except for evaporation which will decrease. In fact, this first observation is an expected result and a concordance with the observed negative impacts of CC at both global (IPCC 2014) and national (MEMEE 2016) scales, especially for temperature and precipitation. Those negative impacts include: the increase of the average air temperature by at least $+3.70{ }^{\circ} \mathrm{C}$, the increase of ETP by at least $18.46 \%$, the decrease of precipitation by $54.16 \%$ (RCP 2.6 ), the decrease of water supply by not less than $59 \%$, the diminution of the stocked volume by $65.19 \%$ (RCP 8.5), and most importantly, the decline of water allocations to users to reach $60.07 \%$ (RCP 8.5). That said, what does not concord with global and national tendencies is the evaporation evolution trend. In fact, the downward trend of evaporation is explained by the decreasing trend projected for the variable water stocked in the reservoir, caused by the decrease of precipitations and water supply to the reservoir. The evaporation here is not to confound with the evaporation part of the evapotranspiration, which as it is seen will increase.

Secondly, except the temperature and the ETP which are related, the two RCPs drain practically the same impact on $\mathrm{HC}$ variables. Regarding this second observation,

Table 1 Change in the average values of the $\mathrm{HC}$ and the management variables between the reference and the projection periods for both RCP 2.6 and 8.5

\begin{tabular}{|c|c|c|c|c|c|c|}
\hline & & \multirow{2}{*}{$\begin{array}{l}\begin{array}{l}\text { Reference } \\
\text { period }\end{array} \\
1986- \\
2015\end{array}$} & \multicolumn{2}{|l|}{ Values } & \multicolumn{2}{|c|}{$\begin{array}{l}\text { Difference }(\%) \text { to } \\
\text { the reference } \\
\text { period }\end{array}$} \\
\hline & & & $\begin{array}{l}\mathrm{RCP} \\
2.6\end{array}$ & $\begin{array}{l}\mathrm{RCP} \\
8.5\end{array}$ & $\begin{array}{l}\mathrm{RCP} \\
2.6\end{array}$ & $\begin{array}{l}\mathrm{RCP} \\
8.5\end{array}$ \\
\hline \multirow[t]{5}{*}{$\mathrm{HC}$ variables } & $\begin{array}{l}\text { Temperature }\left({ }^{\circ} \mathrm{C} /\right. \\
\text { day) }\end{array}$ & 16.61 & 20.32 & 20.71 & $\begin{array}{l}+3.70^{\circ} \\
\mathrm{C}\end{array}$ & $\begin{array}{l}+4.10^{\circ} \\
\mathrm{C}\end{array}$ \\
\hline & ETP (mm/day) & 2.96 & 3.51 & 3.56 & +18.46 & +20.08 \\
\hline & $\begin{array}{l}\text { Evaporation } \\
\left(\mathrm{Mm}^{3} / \text { day }\right)\end{array}$ & 0.118 & 0.082 & 0.080 & -30.52 & -31.81 \\
\hline & $\begin{array}{l}\text { Precipitations } \\
(\mathrm{mm} / \text { day })\end{array}$ & 1.16 & 0.53 & 0.53 & -54.46 & -54.16 \\
\hline & $\begin{array}{l}\text { Water supply } \\
\left(\mathrm{Mm}^{3} / \text { day }\right)\end{array}$ & 2.25 & 0.90 & 0.88 & -59.89 & -60.82 \\
\hline \multirow[t]{2}{*}{$\begin{array}{l}\text { Management } \\
\text { variables }\end{array}$} & $\begin{array}{l}\text { Stocked volume } \\
\left(\mathrm{Mm}^{3} / \mathrm{day}\right)\end{array}$ & 599.89 & 221.02 & 208.84 & -63.16 & -65.19 \\
\hline & $\begin{array}{l}\text { Allocated volume } \\
\left(\mathrm{Mm}^{3} / \text { day }\right)\end{array}$ & 1.88 & 0.797 & 0.75 & -57.92 & -60.07 \\
\hline
\end{tabular}


the similar impacts of both RCP in terms of intensity and trend can be related to three reasons: (1) the horizon of projection 2020-2049 is probably far enough to sense a difference between an optimistic and pessimistic scenario in terms of warming, but it is not far enough to let the RCP 2.6 decreasing emissions to take effect on other aspects of climate much more complex like precipitations (Giorgi et al. 2019); (2) The used RCM and their driven GCM models are likely capable of simulating air temperature directly correlated to greenhouse gases concentration, but still have problem with the simulation of climate variables indirectly related to these gases like precipitations (Schliep et al. 2010); (3) since the projected period is located in the first half of the twenty-first century, it is expected that the difference between scenarios remains small (IPCC 2014; Hawkins and Sutton 2009). This last reason can be more highlighted by looking at the variables evaporation and water supply (obtained using the validated evaporation and hydrologic models), for which the difference between the RCPs is more important, even though they both integrate in their calculation the climate models outputs. For the ETP, more difference between the two RCPs is obtained since it was calculated by the formula of Oudin et al. (2005), which relates the ETP to the temperature directly without requiring any other climate variable. Moreover, the difference between the ETP values for the two RCPs is statistically insignificant at $5 \%$ level $(\mathrm{p}$-value $=0.058)$, which supports the two reasons mentioned.

Thirdly, the difference between the optimistic and the pessimistic RCP is more pronounced for the management variables than the $\mathrm{HC}$ variables: Concerning the third observation, it highlights a valuable conclusion: if following the RCP 2.6 emissions limits will not have immediate and important repercussions on the climate system (IPCC 2014; Marzeion et al. 2018), it would be more likely beneficial to other systems like the capacity of dam's reservoir to regulate water volumes interannually. This conclusion can be supported by the more interesting difference between RCP 2.6 and RCP 8.5 impacts on stocked and allocated volumes. In addition, the cause behind this difference between RCPs impacts for management variables is that the optimized MA has acquired some adaptation capabilities during the sensitivity analysis done in Ahbari et al. (2019). In fact, the optimized approach was defined after testing different scenarios of pluviometry (low, moderate, and high) and water demand (normal and high scenarios).

Fourthly, unlike other variables, the RCP 8.5 would induce less impacts than the RCP 2.6 for the precipitation variable. With regard to this fourth observation, statistical significance tests were applied to the difference between the RCP 2.6 and 8.5 precipitation values, and found it statistically insignificant at $5 \%$ level (pvalue $=0.878$ ). The $95 \%$ confidence interval on the difference between the two RCPs values of precipitation is ] $-0.047 ; 0.040$ [. Therefore, one cannot be sure about the cause responsible of this apparent anomaly: Is it the RCM and the GCM used or it is just a question of sampling.

Fifthly, even though directly related, the precipitations and the water supply variables are not similarly influenced by the RCP selected. In other words, the fifth observation stipulates that while the precipitation is more impacted by the RCP 2.6 , the water supply variable is more influenced by the RCP 8.5 . This may sound 
intriguing, because since the two variables are highly related then they are supposed to behave similarly when they are trained by a given RCP scenario. However, this apparent anomaly could be explained by these two reasons: (1) as it was mentioned before, the difference between the RCP 2.6 and 8.5 for the variable precipitation is not statistically significant; (2) also, the difference between the two RCPs for the variable water supply is statistically insignificant. Thus, the causes behind this situation can be, in addition to a problem in RCM or GCM functionalities, a problem in statistical sampling related to the projection period chosen.

Sixthly, the percentage of change between the reference and the projection periods for all variables is very high. About this last observation, it is necessary to note that all variables values for the RCP 2.6 and 8.5 are statistically significant compared to the reference period at $5 \%$ level ( $\mathrm{p}$-value $<0.0001$ ). This means that according to the used RCMs, a statistically significant $\mathrm{CC}$ during the period 2020-2049 is expected in the basin upstream BEO-AEO compared to the reference period 1986-2015. Moreover, a statistically significant negative impact on the management variables will take place during the same period. For the high intensity of difference between reference and projection periods, it should be known that the values obtained include the uncertainties related to the climate, hydrological, siltation, and evaporation models. So, unlike the direction of change trend, the values of change obtained require a delicate interpretation before making any conclusion.

\section{Intra-annual Evolution of the Variables}

As demonstrated in the subsection before, the projections expect a substantial change in the average value of all studied $\mathrm{HC}$ variables. However, it is necessary and beneficial to analyze the intra-annual evolution of this change, to detect the most impacted months, and to deduct constructive conclusions for some eventual adaptation strategies. Figure 4 represents the intra-annual evolution of the average air temperature in the basin of BEO-AEO.

It is clear from Fig. 4 that the increase of temperature would not concern all months, and the difference between the two RCPs monthly temperature is practically zero. In fact, the hydrological year can be divided into three zones, differentiated by the intensity of temperature increase. Thus, three zones are recognizable: (1) zone 1 (December-January-February) characterized by a very limited increase; (2) zone 2 (November and March) which surrounds zone 1, and it shows a moderate increase of temperature; (3) zone 3 (April to October) known for its high-temperature increase compared to the other zones.

This zonation in the temperature augmentation was also observed in other basins using different RCM and GCM (Bannister et al. 2017; Santer et al. 2018). According to these case studies, the zones' length can change from one month to several months, but the common conclusion is that the winter season had never shown any increase of temperature. The reasons proposed to explain this unique behavior are: (1) climate models are deficient in simulating the Arctic oscillation and the north hemisphere winter climate (Cohen et al. 2012); (2) the high monthly bias was found 


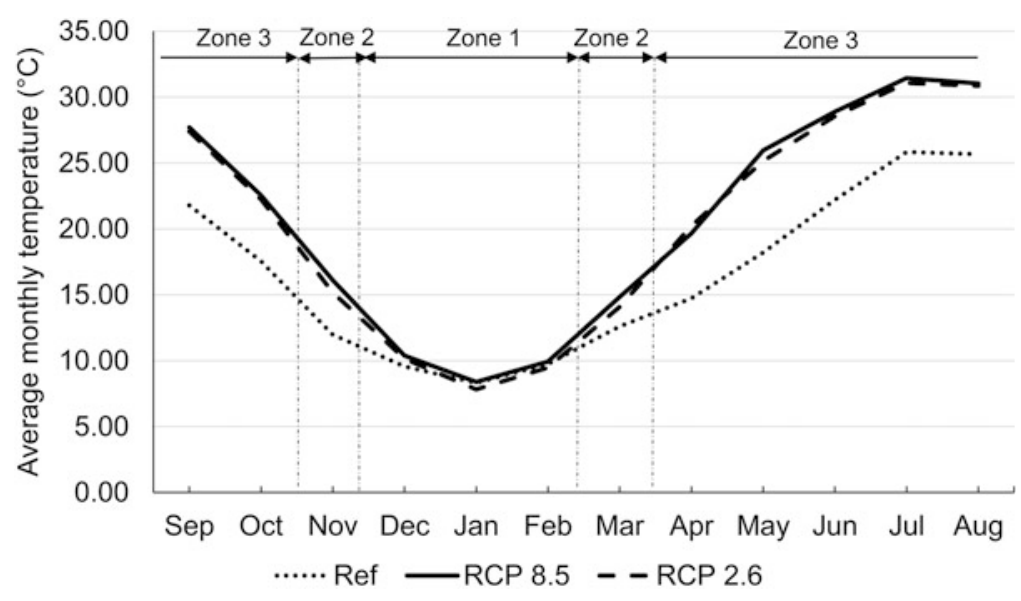

Fig. 4 Intra-annual evolution of the average air temperature under RCP 2.6 and 8.5 in the basin of BEO-AEO

correlated to climate models characterized by sparse horizontal resolution, and thus, to topographical factor (Bannister et al. 2017); (3) the surface-cloud feedback process might be incorrectly represented in climate models (Jiang et al. 2015); (4) the natural cause is not excluded either, because Osuch and Wawrzyniak (2016) have found a comparable seasonality in temperature evolution via the analysis of historical data.

Concerning the difference between the RCPs impacts on monthly air temperature, it was found that the difference between the RCP 8.5 and 2.6 temperature augmentation is statistically significant for November and May only (at $5 \%$ level, p-value equals 0.002 and 0.005 , respectively). On the other hand, the monthly temperature increase compared to the reference period is statistically significant for all months, apart from January and February (p-value equals 0.818 and 0.626 , respectively). These 2 months belonging to zone 1, confirm the characteristics of zone 1 showing, in terms of increasing values, a very limited change.

Like the air temperature, the ETP intra-annual variability presents the same zonation configuration (Fig. 5). Nonetheless, in the case of ETP, the zones' disposition has changed. Hence, the very limited increase zone (zone 1) covers December, January, and February (the change is statistically insignificant for January and February with a p-value reaching 0.926 and 0.672 , consecutively at $5 \%$ level). Then, comes the moderate increase zone (zone 2), which gained some months previously occupied by zone 3 in Fig. 4 (March, April, September, October, and November). Finally, there is zone 3 starting on May and finishing on August, which shows a high increase of ETP compared to other months. All the differences between the reference period and the RCPs are statistically significant for all months covered by zones 2 and 3 .

In reality, the ETP in this study was calculated using a formula that requires only the temperature and the latitude. By consequence, it was expected that the ETP intraannual variability would be similar to the temperature one. Hence, one can wonder 


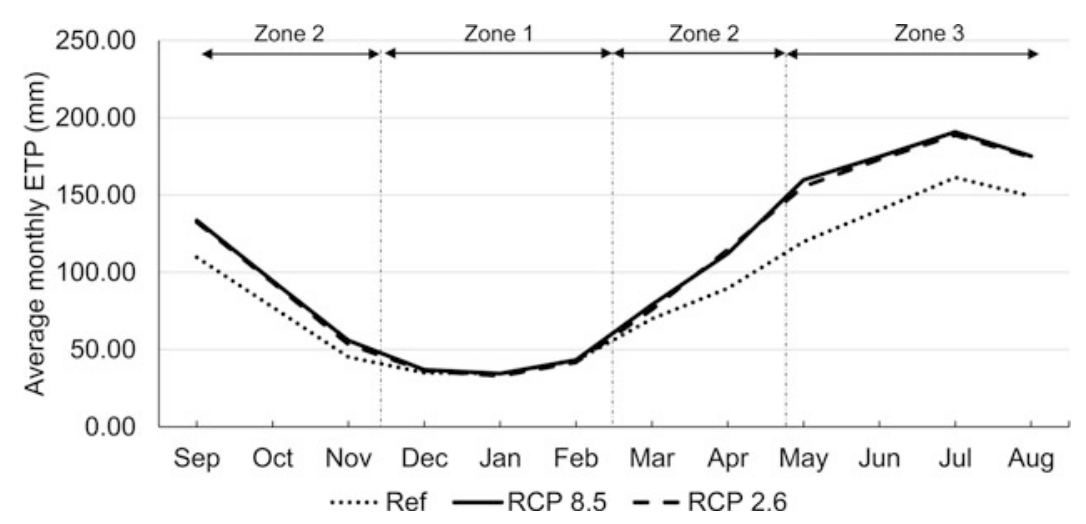

Fig. 5 Intra-annual evolution of ETP under RCP 2.6 and 8.5 forcing in the basin of BEO-AEO

why the pattern of intra-annual variability of temperature and ETP is different? In fact, this is related to the other parameter of the ETP calculation equation: Latitude. Thus, the translation of zones in Fig. 5 compared to Fig. 4 is related to the influence of the latitude parameter, and to its implicit factors such as the global radiation received by the studied area.

Other than the impact zonation, Fig. 5 indicates also that the differentiation between RCP 8.5 and 2.6 impacts on monthly ETP is visually hard to spot. In fact, statistical tests confirm this observation for all months, November, December, and May excepted (p-values equals $0.002,<0.0001$ and 0.005 respectively). Hence, if an issue of climate modeling reason is expulsed, and the natural cause confirmed, this may indicate an interesting classification of months in terms of their ETP responses to greenhouse gases emissions. Consequently, once confirmed, this conclusion might be useful to take into consideration in the adaptation of reservoir operations approaches, so that they became prepared to future CC effects. The zonation remark is also to consider in those adaptation methodologies, since it is repeated in both temperature and ETP results.

For the variables temperature and ETP, the months covered by each zone can be seen differently by each reader, but it is sure that a zonation representing different intra-annual variability is present, and should be investigated further, and eventually taken into consideration in future adaptation strategies.

Regarding the intra-annual variability of evaporation from the reservoir of BEO, Fig. 6 describes a different monthly response of this variable compared to temperature and ETP. In fact, instead of showing months where the change is zero or very limited and others more impacted by $\mathrm{CC}$, the evaporation intra-annual variability concerns all months with a slight difference in intensity from one month to another. That said, it is easy to spot months (December to March) where the difference between projections and reference curves is more pronounced than others (May to September). This is explained by the evolution of water stocked in the reservoir throughout time, it self-controlled by water supply and precipitations seasonality. 


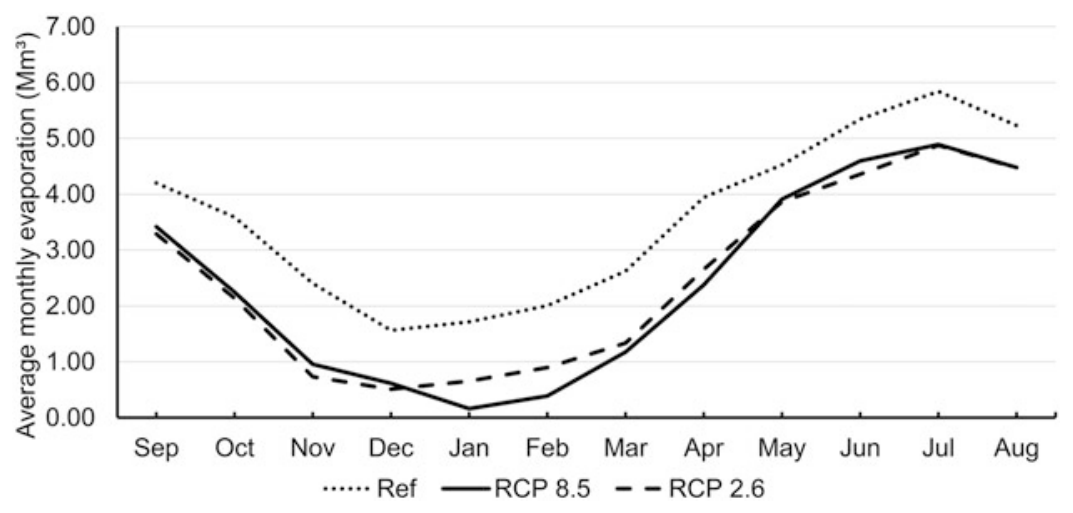

Fig. 6 Intra-annual evolution of evaporation under RCP 2.6 and 8.5 forcing in the reservoir of BEO

As seen, the downward trend of the average evaporation changes detailed in the subsection '3.2.1 Average values change' is detected in all months without exception, in opposition to the variables temperature and ETP. The monthly evaporation diminution shown in Fig. 6 are all statistically significant for all months at 5\% level, with p-values ranging from 0.006 for September to $<0.0001$ for months between October and April. On the other hand, the difference between the two RCPs impacts on monthly evaporation seems to follow a differentiation by months. Hence, there is November, January, and February where the difference between RCP 2.6 and 8.5 is visible and statistically significant (p-value equals 0.044 for the first and $<0.0001$ for the lasts), and the other months where the type of scenario do not apply any statistically relevant difference.

With regard to the variable precipitations, Fig. 7 resumes the evolution of it under reference, RCP 2.6 and RCP 8.5 scenarios. By reading Fig. 7, four fundamental remarks can be deducted: (1) the diminution tendency affects all months, under the two RCPs; (2) the period covered by the rainy season is getting short, especially for the RCP 8.5; (3) The months with very low pluviometry are more frequent (For instance, from June to September); (4) the RCP 8.5 expects a delayed rainy season, while the RCP 2.6 suggests that it would be advanced temporally.

These remarks mean that the basin of BEO-AEO will experience a change in terms of the dominant precipitations type depending on the RCP considered (more solid for the 2.6 RCP, and more liquid for the $8.5 \mathrm{RCP}$ ), a change in the intensity and/ or frequency of summer storms (since the precipitations will be reduced considerably during this season) and of course all the repercussions that will be sensed in the hydrologic regime.

Statistically speaking, although the visual difference between the RCP 2.6 and 8.5 curves for some months (November and March for example) is clear, no significant difference was found for any month.

About the water supply to BEO-AEO and its variation through time, Fig. 8 compares the intra-annual evolution during the reference period and under the 


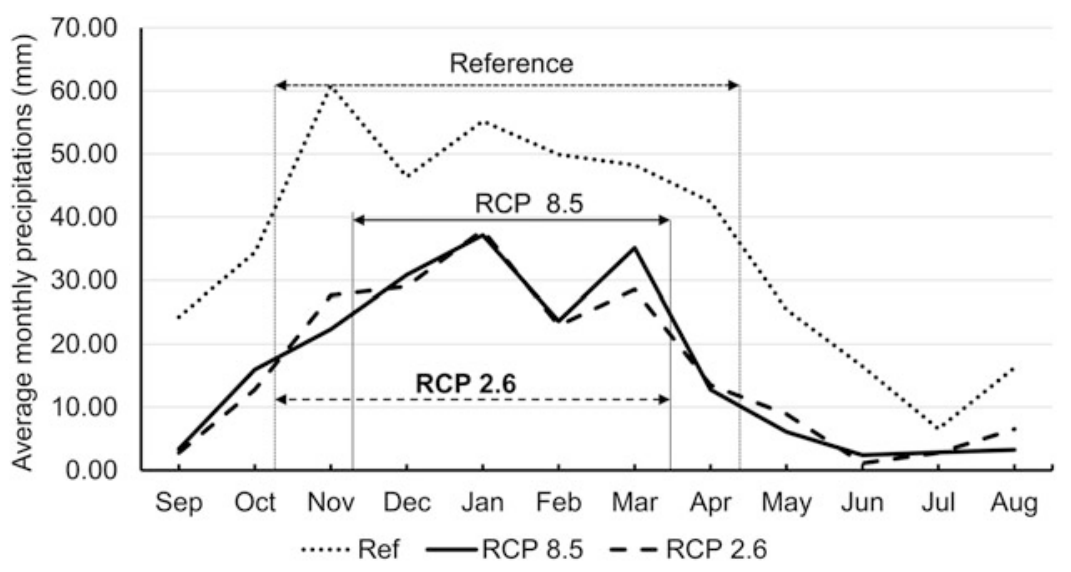

Fig. 7 Intra-annual evolution of precipitations under RCP 2.6 and 8.5 forcing in the basin of BEOAEO

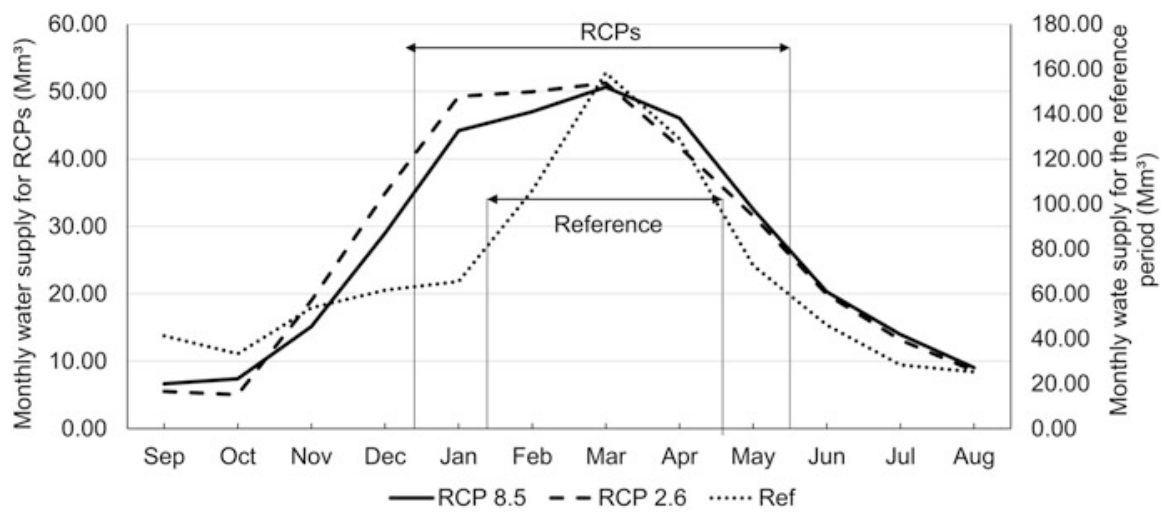

Fig. 8 Intra-annual evolution of water supply under RCP 2.6 and 8.5 in the basin of BEO-AEO

RCPs scenarios. The evolution of water supply concords with the conclusions of Fig. 7 and Table 1, assuming that future water supply will decrease in terms of volume and temporal distribution. In addition, Fig. 8 demonstrates that in parallel with the reduction of its volume drained, the season of "high supply" will prolong temporally compared to the reference period of 1986-2015. Moreover, the change of hydrologic regime from pluvio-nival to pluvial, mentioned in Ahbari et al. (2017), will be accentuated in both RCPs. Thus, the hydrologic peak is located in March, after being culminating in April during the period 1939-1976 (Ahbari et al. 2017). The accentuation of the pluvial regime can be justified when observing the RCPs curves, which present a peak roughly in the form of a plateau, especially for the RCP 2.6, where the plateau covers the months January-February-March. 
In addition, the difference during March between the water supply curves of the reference and the projection periods' is statistically significant (p-value $<0.0001$ at $5 \%$ level), while it was insignificant during the same month for the variable precipitations. This may indicate that the impact of climate projections on March water supply was not induced via a change in March precipitations, but it is caused by another factor. In fact, the presumed vector of change is an advanced melting of the solid precipitations that occurred in previous months (especially for the RCP 2.6 where the dominant form of precipitations is the solid one), accelerated by the projected temperature increase. Then, if this is the case, the conclusions mentioned by other studies and confirmed in this chapter, about the incapacity of the RCM and GCM models to simulate the winter temperature increase, are reinforced again.

Additionally, in contradiction to the observation about dominant precipitation seen in Fig. 7, the water supply evolutions for the RCP 2.6 and 8.5 do not match the type of regimes expected.

Even though the solid precipitations are expected in RCP 2.6, the hydrologic regime is almost the same as for 8.5 on which liquid precipitations are more dominant. This is explained by the fact that the solid precipitations will not wait too long to melt, since the increase in temperature already mentioned provoke an advanced melting, and will not wait until the spring season. If this explanation is correct, this means that the reasons stated before about the stability of temperature in the winter season are correct, and the models are really encountering issue with the simulation of climate during this season.

\section{Impacts on the Performances of BEO-AEO Reservoir}

After running the assessment procedure detailed in Fig. 2 for the RCPs 2.6 and 8.5, the performances of the optimized MA of BEO-AEO under CC projections were assessed, via the calculation of the six most important criteria. Table 2 details the results obtained at a daily time-step scale.

According to Table 2, except the standard deviation of allocations, all aspects of performance will be deteriorated under the two emissions scenarios. Therefore, the percentage of deterioration can reach $+157.48 \%$ (RCP 8.5 ) for the daily deficit, $-68.77 \%$ (RCP 8.5 ) for the daily reliability, not less than $-58.98 \%$ (RCP 2.6$)$ in the case of the resilience and sustainability and at least $+58.88 \%$ (RCP 2.6 ) of vulnerability deterioration. Moreover, it is proved by Table 2 that the vulnerability is the less impacted aspect, and the deficit the most damaged one.

Oppositely, the standard deviation of water allocations will be improved and its daily value will fluctuate between $17.77 \%$ (RCP 8.5) and 19.36\% (RCP 2.6). The reason explaining this improvement is that the establishment of the optimized MA included a phase where the optimization of the releases to users has been performed. So, performing this update permitted to the MA to acquire an attitude to keep the variability of allocations minimal, under stressing climate circumstances.

Furthermore, and unlike the $\mathrm{HC}$ variables, the type of the scenario chosen appears to have an effect more considerable on the performances displayed by the BEO-AEO 
Table 2 Average daily values of the performance criteria of BEO-AEO calculated for the reference and projection periods

\begin{tabular}{l|l|l|l|l|l}
\hline \multirow{2}{*}{} & \multicolumn{3}{l}{} & \multicolumn{2}{l}{$\begin{array}{l}\text { Difference to the } \\
\text { reference (\%) }\end{array}$} \\
\cline { 2 - 7 } & Reference & RCP2.6 & RCP8.5 & RCP 2.6 & RCP 8.5 \\
\hline Deficit & 26.68 & 67.01 & 68.70 & +151.16 & +157.48 \\
\hline Reliability & 25.50 & 8.58 & 7.96 & -66.33 & -68.77 \\
\hline Resilience & 11.16 & 4.58 & 4.18 & -58.98 & -62.50 \\
\hline Vulnerability & 47.76 & 75.87 & 77 & +58.88 & +61.24 \\
\hline Sustainability & 24.59 & 9.82 & 9.15 & -60.04 & -62.789 \\
\hline Standard deviation of allocations & 38.73 & 19.36 & 17.77 & -50.01 & -54.10 \\
\hline
\end{tabular}

system. This confirms the conclusion mentioned before that: if the RCP 2.6 emissions guidelines are followed, it is certain that the climate will need decades to restore its regular conditions, but the systems impacted by this climate (the reservoir operations in this case) will rapidly start to show substantial enhancement.

By consequence, in the case of BEO-AEO complex, the aspects of performance that will manifest intensively this attitude are the daily deficit and the resilience. In fact, the reason behind the fast response of the deficit criterion is similar to the reason behind the improvement of allocations variability. Regarding the resilience, it is related to the fact that the choice of this optimized approach as the best one (Ahbari et al. 2019), was preceded by a sensitivity analysis towards different conditions (including varying pluviometry and water demand scenarios). Therefore, the different scenarios tested had likely helped in adapting the approach to extreme conditions, and by consequence, they improved its resilience capacities. Furthermore, the rapid response of the resilience criterion to the change of RCP can also be explained by the fact that, as shown in Ahbari et al. (2019), the resilience of BEO-AEO was the aspect of performance on which the manager of this reservoir complex have focused while calibrating the MA for the last time. This may indicate that if a regular update of the current MA was done, by including the resilience criterion in the objective function, the resilience may show similar results as those shown by the standarddeviation of allocations.

Overall, the results of the $\mathrm{CC}$ effects assessment present a clear tendency to have negative impacts on both the hydro-climatology of the basin of BEO-AEO and on the performances of the complex. In fact, the impacts projected concord with those reported in the literature (McSweeney et al. 2010; Ouraich 2014; MEMEE 2016; Filahi et al. 2017) in terms of trend, but not always concerning the intensity of change. For instance, McSweeney et al. (2010) and Ouraich (2014) stated a range of temperature variation across Morocco oscillating between +1.5 and $+3.5{ }^{\circ} \mathrm{C}$ for 2060 , and a maximum decrease of precipitations reaching 52\%. Nevertheless, MEMEE (2016) mentioned that by 2065, air temperature in Morocco would increase from $+0.5{ }^{\circ} \mathrm{C}$ to $+2{ }^{\circ} \mathrm{C}$, and precipitations change is projected to vary between $+10 \%$ and $-20 \%$, depending on the region and the RCP scenario. 
Nonetheless, it is necessary to mention that while the projected temperature and precipitations are averaged over all the catchment areas, the temperature, precipitation, and ETP of the reference period are gauge-based series. Thus, this may be explaining some of the differences. Additionally, water supplies are also based on average precipitation over the whole basin during the projection period, while in the reference it is based on the average of six gauges. Moreover, since all the performance values are based on water supply, then even these performance evolution compared to the reference period is to take with precautions.

The differences observed could be caused by the bias-corrected climate projections used in this study. In this chapter, the use of the CORDEX bias-corrected and downscaled data was dictated by the fact that neither the availability of meteorological stations inside and around the basin (especially for temperature), or the accessibility to those data was possible at the time of completion of this study. Therefore, the use of the available ones in the training and testing of a statistical downscaling and/or bias-correction method will never converge to acceptable results. These problems of network representativeness and limitation on climate model validation were reported by several authors (Filahi et al. 2017). So, the intensity of change in these conditions will never be accurate, even without counting the uncertainties driven by the different models and data.

Nevertheless, the differences can also be related to the various uncommon aspects between the materials and methods used in this chapter, and those employed in other studies, including: (1) the choice of RCM, GCM, and all the specifications that go in parallel (domain type, spatial resolution, ensemble calculation...) (Fantini et al. 2018; von Trentini et al. 2019); (2) the climate and hydrological models characteristics (Lespinas et al. 2014); (3) the downscaling and bias correction methods used and all the uncertainties they drive during training and testing (Teutschbein and Seibert 2012; Räty et al. 2018); (4) the choice of the reference, the projection periods, and the time step of projection (daily, monthly, or annually) used; (5) the area studied by each chapter (whole country, neighboring basin, neighboring city...).

In addition, to attenuate this disagreement between impacts assessment studies, it is recommended to proceed to the accomplishment of the following guidelines: (1) simple RCM assessment via a validation of the RCM simulations over a historical period; (2) advanced RCM assessment via a sensitivity analysis of RCM tuning parameters (Bucchignani et al. 2016); (3) The use of ensemble RCMs simulations instead of single RCM outputs, due to the benefits proven by this option (Phillips and Gleckler 2006; Filahi et al. 2017); (4) the assessment and selection of the best ensemble RCMs prediction method (Duan and Phillips 2010) without being influenced by the eventual negative impacts of ensemble mean RCM use.

However, this disagreement between studies, about the magnitude of change, is not only specific to the basin of BEO, but it is well-known worldwide at catchment scale (Sellami et al. 2016). Furthermore, the projections of CC can also differ in sign not only in magnitude (Koutsouris et al. 2010; Nassopoulos et al. 2012).

In addition, the intensity of change is not the ultimate objective in CC assessment studies, nor it is the aim of this chapter. But, the important is to prove to managers 
that impacts are coming, and adaptation actions are highly recommended. Moreover, the manager should know that even with an optimized MA, without regular updates, the future performances will be heavily affected. In fact, with all the uncertainties trained by the climate, hydrological, and other models used, the use of these projections, directly, to adapt the current MAs would be useless, or even counterproductive.

In reality, the climate projections can be used indirectly by exploiting common conclusions like those mentioned in this chapter (the trend of change, the zonation in the impact of $\mathrm{CC}$ on the variability of temperature and ETP, the change in precipitation dominant form, the change in hydrologic regime, which months are more affected, which performance aspects are more responsive to adaptability, which ones are more impacted by CC...).

Hence, the current MA can be modified by adding additional parameters, and/or optimized by testing various operations conditions to take into consideration those expected change. Once those modifications are applied to the current MA, the manager can update his approach regularly to implement each time the trend of change and its intensity. Furthermore, the manager can look for the best update pattern of this new approach, by comparing different update configuration (each year, each $n$ years...).

For instance, in our example, before evaluating the impacts of $\mathrm{CC}$ on the performances of BEO-AEO, Ahbari et al. (2019) proceeded to the update and optimization of the releases formulae. Thus, when analyzing the results of performance projections, the standard deviation of water allocations was the only criterion which had experienced an improvement of its daily value.

\section{Conclusions and Perspectives}

The aim of the chapter was to assess the impacts of future $\mathrm{CC}$ projections on the $\mathrm{HC}$ variables, management variables, and the performances of the complex of BEOAEO. To accomplish this objective, a typical top-down CC assessment procedure was followed including the use of optimistic and pessimistic emissions scenarios, RCM ensemble-mean, and prevalidated models (hydrological, siltation, evaporation, and reservoir management models). The climate projections data used were from the bias-corrected CORDEX data specific to EUR-11 spatial domain. Once the typical assessment procedure was run, the results were analyzed via: average values change, intra-annual variability, and performance criteria.

The results obtained show negative impacts for both HC (evaporation excepted) and management variables and all the performance aspects (the standard deviation of allocations excepted) of BEO-AEO. In general, the trends of $\mathrm{HC}$ variables change concord with other studies focusing on Morocco. Particularly, the projections expect an increase of air temperature and ETP, a downward tendency of precipitations, water supply, evaporation, stocked volume in the reservoir of BEO, allocated volumes to users. In terms of performances, and except the standard-deviation of allocations, negative trends of evolution are projected for all performance criteria: increase of deficit and vulnerability and decrease of reliability, sustainability, and 
resilience. Oppositely, the variability of water allocations will be improved under the two RCPs. This improvement is related to the phase of optimization of the releases that preceded this work. Concerning the intra-annual variability of the $\mathrm{HC}$ variables, the following conclusions are the most important ones: the zonation in terms of the impacts of CC on the variability of temperature and ETP, the change in precipitation dominant form depending on the RCP chosen, the accentuation of the pluvial hydrological regime, the probable advanced snow melting due to the increase of temperature, the limited difference between the impacts of the two RCPs on the majority of variables and months.

Finally, it is sure that the intensity of the projected CC mentioned in this chapter, and the one reported in other papers are not similar, but all of them have a consensus regarding the tendency of this change: Negative impacts are expected. Therefore, actions should be taken in order to adapt these infrastructures to CC effects.

\section{References}

AgriMetSoft (2017) Rotation of coordinates based on CORDEX domains [Computer software]. http://www.agrimetsoft.com/CordexCoordinateRotation.aspx. Accessed 10 May 2020

Ahbari A, Stour L, Agoumi A (2017) The dam reservoir of Bin El Ouidane (Azilal, Morocco) face to climate change. Int J Sci Eng Res 8(5):199-203. https://doi.org/10.14299/ijser.2017.05.013

Ahbari A, Stour L, Agoumi A et al (2018a) Estimation of initial values of the HMS model parameters: application to the basin of Bin El Ouidane (Azilal, Morocco). J Mater Environ Sci 9(1):305-317. https://doi.org/10.26872/jmes.2018.9.1.34

Ahbari A, Stour L, Agoumi A et al (2018b) Sensitivity of the HMS model to various modelling characteristics: case study of Bin El Ouidane basin (High Atlas of Morocco). Arab J Geosci 11:549. https://doi.org/10.1007/s12517-018-3911-x

Ahbari A, Stour L, Agoumi A et al (2018c) A simple and efficient approach to predict reservoir settling volume: case study of Bin El Ouidane reservoir (Morocco). Arab J Geosci 11:591. https://doi.org/10.1007/s12517-018-3959-7

Ahbari A, Stour L, Agoumi A (2019) Ability of the performance criteria to assess and compare reservoir management approaches. Water Resour Manag 33(4):1541-1555. https://doi.org/10. 1007/s11269-019-2201-z

Bannister D, Herzog M, Graf HF et al (2017) An assessment of recent and future temperature change over the Sichuan Basin, China, using CMIP5 climate models. J Clim 30(17):6701-6722. https://doi.org/10.1175/JCLI-D-16-0536.1

Borison A, Hamm G (2008) Real options and urban water resource planning in Australia. Water Services Association of Australia occasional paper (20). Water Services Association of Australia, Melbourne

Brient F (2020) Reducing uncertainties in climate projections with emergent constraints: concepts, examples and prospects. Adv Atmos Sci 37:1-15. https://doi.org/10.1007/s00376-019-9140-8

Brown C, Ghile Y, Laverty M et al (2012) Decision scaling: linking bottom-up vulnerability analysis with climate projections in the water sector. Water Resour Res 48:W09537. https:// doi.org/10.1029/2011WR011212

Bucchignani E, Cattaneo L, Panitz H-J et al (2016) Sensitivity analysis with the regional climate model COSMO-CLM over the CORDEX-MENA domain. Meteorog Atmos Phys 128(1): 73-95. https://doi.org/10.1007/s00703-015-0403-3

Bussi G, Francés F, Horel E et al (2014) Modelling the impact of climate change on sediment yield in a highly erodible Mediterranean catchment. J Soils Sediments 14:1921-1937. https://doi.org/ 10.1007/s11368-014-0956-7 
Cohen JL, Furtado JC, Barlow MA et al (2012) Arctic warming, increasing fall snow cover and widespread boreal winter cooling. Environ Res Lett 7:014007. https://doi.org/10.1088/17489326/7/1/014007

Condie SA, Webster IT (1997) The influence of wind stress, temperature, and humidity gradients on evaporation from reservoir. Water Resour Res 33(12):2813-2822

Duan Q, Phillips TJ (2010) Bayesian estimation of local signal and noise in multimodel simulations of climate change. J Geophys Res 115:D18123. https://doi.org/10.1029/2009JD013654

Fantini A, Raffaele F, Torma C et al (2018) Assessment of multiple daily precipitation statistics in ERA-interim driven med-CORDEX and EURO-CORDEX experiments against high resolution observations. Clim Dyn 51:877-900. https://doi.org/10.1007/s00382-016-3453-4

Filahi S, Tramblay Y, Mouhir L et al (2017) Projected changes in temperature and precipitation in Morocco from high-resolution regional climate models. Int J Climatol 37(14):4846-4863

Giorgi F, Jones C, Asrar G (2009) Addressing climate information needs at the regional level: the CORDEX framework. World Meteorol Organ Bull 58:175-183

Giorgi F, Raffaele F, Coppola E (2019) The response of precipitation characteristics to global warming from climate projections. Earth Syst Dynam 10:73-89. https://doi.org/10.5194/esd-1073-2019

Hashimoto T, Stedinger JR, Loucks DP (1982) Reliability, resiliency, and vulnerability criteria for water resource system performance. Water Resour Res 18(1):14-20. https://doi.org/10.1029/ WR018i001p00014

Hausfather Z, Peters GP (2020) Emissions - the 'business as usual' story is misleading. Nature 577:618-620

Hawkins E, Sutton R (2009) The potential to narrow uncertainty in regional climate predictions. Bull Am Meteorol Soc 90:1095-1107. https://doi.org/10.1175/2009BAMS2607.1

IPCC (2014) Working group I contribution to the IPCC fifth assessment report climate change (2014) the physical science basis. Cambridge University Press, Cambridge, UK/New York

Jiang D, Tian Z, Lang X (2015) Reliability of climate models for China through the IPCC third to fifth assessment reports. Int J Climatol 36(3):1114-1133. https://doi.org/10.1002/joc.4406

Koutsouris AJ, Destouni G, Jarsjö J et al (2010) Hydro-climatic trends and water resource management implications based on multi-scale data for the Lake Victoria region, Kenya. Environ Res Lett 5:034005

Lespinas F, Ludwig W, Heussner S (2014) Hydrological and climatic uncertainties associated with modeling the impact of climate change on water resources of small Mediterranean coastal rivers. J Hydrol 511:403-422. https://doi.org/10.1016/j.jhydrol.2014.01.033

Looks DP (1997) Quantifying trends in system sustainability. Hydrol Sci J 42(4):513-530. https:// doi.org/10.1080/02626669709492051

Marzeion B, Kaser G, Maussion F et al (2018) Limited influence of climate change mitigation on short-term glacier mass loss. Nat Clim Change 8:305-308. https://doi.org/10.1038/s41558-0180093-1

McMahon TA, Adeloye AJ, Sen-Lin Z (2006) Understanding performance measures of reservoirs. J Hydrol 324:359-382. https://doi.org/10.1016/j.jhydrol.2005.09.030

McSweeney C, New M, Lizcano G (2010) UNDP climate change country profiles: Morocco. http:// country-profiles.geog.ox.ac.uk/. Accessed 18 Dec 2018

Means E, Laugier M, Daw J (2010) Decision support planning methods: incorporating climate change uncertainties into water planning. Water Utility Climate Alliance White Paper. https:// www.wucaonline.org/assets/pdf/pubs-whitepaper-012110.pdf. Accessed 10 May 2020

MEMEE (2016) 3éme Communication Nationale du Maroc à la Convention Cadre des Nations Unies sur les Changements Climatiques. http://unfecc.int/resource/docs/natc/marnc3.pdf. Accessed 18 Dec 2018

Morgan M, Dowlatabadi H, Henrion et al (2009) U.S. Climate Change Science Program. Synthesis and assessment product 5.2. Best practice approaches for characterizing, communicating and incorporating scientific uncertainty in climate decision making. https://keith.seas.harvard.edu/ files/tkg/files/sap_5.2_best_practice_approaches_for_characterizi.pdf. Accessed 10 May 2020 
Nassopoulos H, Dumas P, Hallegatte S (2012) Adaptation to an uncertain climate change: cost benefit analysis and robust decision making for dam dimensioning. Clim Chang 114:497-508. https://doi.org/10.1007/s10584-012-0423-7

Osuch M, Wawrzyniak T (2016) Inter- and intra-annual changes in air temperature and precipitation in western Spitsbergen. Int J Climatol 37(7):3082-3097. https://doi.org/10.1002/joc.4901

Oudin L, Hervieu F, Michel C et al (2005) Which potential evapotranspiration input for a lumped rainfall-runoff model? Part 2 - towards a simple and efficient potential evapotranspiration model for rainfall-runoff modelling. J Hydrol 303(1-4):290-306. https://doi.org/10.1016/j. jhydrol.2004.08.026

Ouraich I (2014) Agriculture, climate change, and adaptation in Morocco: a computable general equilibrium analysis. $\mathrm{PhD}$ thesis, Purdue University

Phillips TJ, Gleckler PJ (2006) Evaluation of continental precipitation in 20th century climate simulations: the utility of multimodel statistics. Water Resour Res 42(3):W03202. https://doi. org/10.1029/2005WR004313

Räty O, Räisänen J, Bosshard T et al (2018) Intercomparison of univariate and joint bias correction methods in changing climate from a hydrological perspective. Climacteric 6:33. https://doi.org/ 10.3390/cli6020033

Sandoval-Solis S, McKinney DC, Loucks DP (2011) Sustainability index for water resources planning and management. J Water Resour Plan Manag 137(5):381-390. https://doi.org/10. 1061/(ASCE)WR.1943-5452.0000134

Santer BD, Po-Chedley S, Zelinka MD et al (2018) Human influence on the seasonal cycle of tropospheric temperature. Science 361(6399):eaas8806. https://doi.org/10.1126/science. aas 8806

Schliep EM, Cooley D, Sain SR et al (2010) A comparison study of extreme precipitation from six different regional climate models via spatial hierarchical modeling. Extremes 13:219-239

Sellami H, Benabdallah S, La Jeunesse I et al (2016) Quantifying hydrological responses of small Mediterranean catchments under climate change projections. Sci Total Environ 543(B):924 936. https://doi.org/10.1016/j.scitotenv.2015.07.006

Singh VL, Jain SK, Singh PK (2019) Inter-comparisons and applicability of CMIP5 GCMs, RCMs and statistically downscaled NEX-GDDP based precipitation in India. Sci Total Environ 697:134163. https://doi.org/10.1016/j.scitotenv.2019.134163

Teutschbein C, Seibert J (2012) Bias correction of regional climate model simulations for hydrological climate-change impact studies: review and evaluation of different methods. J Hydrol 12 (29):456-457. https://doi.org/10.1016/j.jhydrol.2012.05.052

Tofiq FA, Guven A (2014) Prediction of design flood discharge by statistical downscaling and general circulation models. J Hydrol 517:1145-1153. https://doi.org/10.1016/j.jhydrol.2014.06. 028

Van Vuuren DP, Edmonds J, Kainuma M et al (2011) The representative concentration pathways: an overview. Clim Chang 109:5-31. https://doi.org/10.1007/s10584-011-0148-z

von Trentini F, Leduc M, Ludwig R (2019) Assessing natural variability in RCM signals: comparison of a multi model EURO-CORDEX ensemble with a 50-member single model large ensemble. Clim Dyn 53:1963-1979. https://doi.org/10.1007/s00382-019-04755-8

Zhang W, Liuab P, Wangac $\mathrm{H}$ et al (2017) Reservoir adaptive operating rules based on both of historical streamflow and future projections. J Hydrol 553:691-707. https://doi.org/10.1016/j. jhydrol.2017.08.031 
Open Access This chapter is licensed under the terms of the Creative Commons Attribution 4.0 International License (http://creativecommons.org/licenses/by/4.0/), which permits use, sharing, adaptation, distribution and reproduction in any medium or format, as long as you give appropriate credit to the original author(s) and the source, provide a link to the Creative Commons license and indicate if changes were made.

The images or other third party material in this chapter are included in the chapter's Creative Commons license, unless indicated otherwise in a credit line to the material. If material is not included in the chapter's Creative Commons license and your intended use is not permitted by statutory regulation or exceeds the permitted use, you will need to obtain permission directly from the copyright holder.

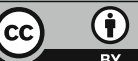

